\title{
Economic-Political Cyclicality or: Is There Any Good in Economic-Political Cycles Theory?
}

\author{
Ofer Arian ${ }^{1}$, Javier Simonovich ${ }^{2} \&$ Moshe Sharabi $^{3}$ \\ ${ }^{1}$ The Max Stern Emek Yezreel College, Emek Yezreel, Israel \\ ${ }^{2}$ Department of Human Services, Yezreel Valley Academic College, Emek Yezreel, Israel \\ ${ }^{3}$ Department of Sociology and Anthropology, Yezreel Valley Academic College, Emek Yezreel, Israel \\ Correspondence: Ofer Arian, The Max Stern Emek Yezreel College, Emek Yezreel, Israel. E-mail: \\ ofera@yvc.ac.il
}

Received: March 31, 2016

Accepted: May 15, 2016 Online Published: August 30, 2016

doi:10.5539/jpl.v9n7p102

URL: http://dx.doi.org/10.5539/jpl.v9n7p102

\begin{abstract}
This article deals solely with the analysis of economic-political cycles during the past decade. The reader will find here a limited attempt to point out the present status of the arena while it is used as an analytical tool.

This article offers a theoretical examination of the concept economic-political cyclicality and discusses the development of patterns of thinking related to it. The article presents the main principles of the idea, explains the basic assumptions, which the various approaches to it have in common, and points out the differences of opinion among the leading theorists. The analysis shows that there are numerous limitations of the theoretical tools and that great caution should be used in regard to conclusions arrived at on the basis of analyses that use these instruments. In this area, as in other areas of study that bring together economics and politics, a great deal still needs to be done. We argue that whereas those who deal with business cycles the attempt are always the same. Simply stated, they deal with specific events in which decisions are made for the purpose of achieving the maximum political-social gain in (conscious) exchange for conceding optimum macro-economic gain.
\end{abstract}

Keywords: economic-political cyclicality, theoretical perspective, policy optimization, reaction functions

\section{Introduction}

Politicians who must confront the test of public scrutiny make decisions about economic policy in the political arena. A realistic assessment of an economic policy's degree of success can only be determined by someone who is capable of evaluating both the desired economic outcomes and the institutional context in which they will be implemented. In light of this insight, three areas of academic research have developed over the last three decades of the twentieth century that highlight the mutual influence of economic and political forces: 1 . political business cycles; 2. policy optimization and reaction functions; 3. economic influences on voting patterns.

In many respects the division between these areas of research is artificial, deriving from the limitations of the available research tools. For this reason and because the present discussion of this topic must be delimited, the article will deal solely with the analysis of economic-political cycles during the past decade. This is a limited attempt to point out the present status of the arena while it is used as an analytical tool.

In the discussion below, the study of economics and political science, overlap. Economists, political scientists, and researchers from related fields engage in this discourse, with each one of these disciplines making a unique contribution. At the same time, the blending of specialties may cause difficulties, one of them being a certain degree of imprecision, which may result from using different concepts in a similar manner. In order to avoid this inevitable impediment, we will begin by clarifying the terminology that will be used in the discussion below.

\section{What Is Economic-Political Cyclicity?}

The literature in the field of economics makes frequent use of the term "business cycles," whereas political scientists often refer to the term "economic-political cycles" or "political-business cycles." Both terms deal with cyclical phenomena and seek to explore their significance. But whereas those who deal with business cycles attempt to understand the nature and significance of cycles (from the macro and micro points of view), those who study the economic-political cycle devote their attention to instances in which there is an (ostensible or real) 
attempt to link cyclical economic functioning and cyclical political functioning. Simply stated, they deal with specific events in which decisions are made for the purpose of achieving the maximum political-social gain in (conscious) exchange for conceding optimum macro-economic gain. Hence, at least in the context of the present discussion, not all business cyclical functioning is also economic cyclical functioning, although the first type of cyclicality is a necessary (but not sufficient) condition for the discussion of the second type.

As stated, cyclical patterns of economic functioning - peaks and low points - are well-known and in economics these fluctuations are called "business cycles." The mechanisms that cause repeated shifting from high to low points have been the main interest of macro-economic theory for a very long time mainly due to the realization that cyclicality can create problems and lead to instability. Despite continuous research efforts and the major importance of this topic for understanding the dynamics of macro-economics, no one universally accepted theory exists today that explains the fluctuations of business activity in the economy (Melnick, 2002).

It is important to note that cyclicality in and of itself is not unique to the area of economics. In the political arena, recurring peaks and valleys may be identified in periods preceding elections, the initial post-election phase, and as new elections approach. By virtue of the fact that in democratic societies, the public entrusts the reigns of government in the hands of elected officials - for a specified time and under certain rules - there is a basis for the conviction that political functionaries will (or will at least attempt to) influence economic fluctuations Wilensky (2002).

\section{The Politician Intervention in the Economy}

Drazen (2002) explains that the problem in the political sphere is the existence of political forces that promote fiscal expansion. In his opinion, the reason for this stems from three basic trends. The first, which he credits to Niskanen (1971), is that bureaucratic behavior is explained by maximization of the budget (since the power of the bureaucrat is measured in relation to the size of his budget). The second is that budgetary restraint is, in effect, "public merchandise" that gives rise to debates about who must bear the cost of the subsequent cutbacks. The third is that institutional and budgetary rules in bureaucratic systems can divert and change economic goals.

What makes it possible for the government to intervene in a market economy? How does the government actually implement its intention to coordinate the cyclicality of the economy with that of politics? What (political or economic) decisions and alternatives do economic leaders have to choose from? To what extent, if at all, is it appropriate to distinguish between a decision that is purely economic, purely political, or a mixture of both (for economic or political purposes)?

This inquiry begins with the debate generated by the publication of Adam Smith's theory of economics at the end of the eighteenth century. From that time forward until the middle of the twentieth century, the debate centered around the question: which economic theory is the most correct; which one can best explain the nature of the optimal allocation of economic resources? This debate is a thing of the past. Today, there is no one who disputes the advantage of the free market, i.e., the competitive approach (in terms of economics-product). At the same time, there is an ongoing controversy about the degree of public responsibility towards each individual in society. Consequently, opinions are divided about the proper place of the government in the market economy (since it is responsible for remedying "economic injustice" and achieving social justice in keeping with the moral norms of the society).

It will be recalled that in 1936, the eminent economist, John Maynard Keynes, in his The General Theory of Employment, Interest and Money, declared that in order to rescue Western society from a severe economic crisis, government must intervene in economic activity so as to bring about a growth of economic products. He claimed that the market economy could not, in every instance, rescue itself from recession. The explanation offered in Keynes's book was accepted enthusiastically by Western nations both because, in retrospect, it seemed to explain the success of the United States in extricating itself from the Depression of 1929-1930 and it provided the economic-theoretical justification, which invited governments to intervene in the market economy on an ongoing basis.

In those countries that adopted Adam Smith's An Inquiry Into The Nature and Causes of The Wealth of Nations (1776), (Note 1) this was considered an unacceptable option. Liviatan (2002) takes the position that the attitude toward anti-cyclical policies (Note 2) has changed dramatically during the last fifty years. He points out that in the 1950s and the beginning of the 1960s; the Keynesian approach was dominant (encouraging government intervention by means of fiscal growth). In the 1960s and 1970s, the global economy descended into stagflation and there was concern about the harmful effects of continuous inflational developments. Because of these fears, the primacy of the Keynesian approach was abandoned in favor of the "monetary revolution" and the development of "rational expectations" approaches and the games theory ( as a practical tool of decision 
making) . Added to this in recent years has been the trend toward financial integration (known as "globalization") that imposes additional limitations on the planning and implementation of anti-cyclical policies.

The development of economic theory, and parallel to it, the growing awareness of human and civil rights in modern democratic societies (Note 3) have also contributed (separately and in combination) to the continued manipulation of economic-political cyclicality. In other words, Keynes's economic theory brings Western governments back to the economic marketplace, albeit for a limited time. But the inflation, unemployment, and other economic problems that developed in Western countries following the adoption of this theory led to the emergence of complementary theories, which were all based on the assumption that economic "malfunctions" arise from government intervention in the marketplace. However, such changes in awareness have not been deterring various Western governments from intervening (whether overtly, covertly, or both) in the economy. What has been changing is the claim that justifies the ongoing intervention. In contrast to Keynes - whose justification for government intervention was the need to deal with economic crises - from the end of the Second World War and thereafter, the rationale that favors intervention has been linked to the idea of "the welfare state" and the need to provide "public products" (Note 4) (which are thought of as vested civil rights). It is not my intention at this time to discuss issues related to the welfare state; (Note 5) suffice it to say that the desire to implement welfare policies has also provided the long-term rationale for government intervention in the marketplace, intervention that enabled, even if only theoretically, economic-political manipulation.

\section{The Common Assumptions of the Models}

From this point forward, ideas were being developed with regard to the enormous potential built into the concept of coordinating the economic and political cycles. Naturally, this idea is based on several fundamental assumptions: awareness of the fact that both economic activity and political activity function in cycles; an awareness that there is no essential need for synchronization between these two spheres; the knowledge that perspectives of time in economics and politics are essentially different from one another; the belief that intentional coordination between the cycles can offer political gains for those who support it.

In the following discussion, I will provide a concise presentation of the main models that have been developed in this area. Naturally, I will also discuss the main aspects of the debate surrounding these models. Before doing so, however, it is, I believe, extremely important to demarcate the controversy between the advocates and opponents of the idea of economic and political cyclicality. It is incorrect to believe that the supporters diverge from the detractors over the issue of the existence of business cycles (economic cyclicality) and political cycles. Both camps agree that the two types of cycles exist. It is also erroneous to think that the difference between the two groups relates to the firm belief that coordination between the two cycles is possible, since it is true that such coordination exists in some cases and that some may attempt to reap (electoral or other) benefits from cyclical coordination of one sort or another. Both camps agree that this is possible and sometimes even efficacious.

So what is the actual source of the controversy? It is about one and only one question: how clear is the conclusion that a specific instance of such coordination is the natural outcome of a defined political initiative? Opponents of economic-political cyclicality use various explanations to support their dissent. They may claim that in a specific instance, the relationship between the result and the person who was thought to be behind it is not clear, or that other, intervening variables may have been at play. They may cast doubt on the efficacy of the initiative for its planners, or deny the effectiveness of the tool that was used, all without negating the idea of economic-political cyclicality in principle. Naturally, they may also reject outright the existence of any connection. It is this complexity which apparently explains the fact that researchers have persisted in examining these questions since the middle of the twentieth century, and continue to pursue this issue to this very day. Still, it must be noted that disagreement exists even among those who accept this approach, an aspect that I will address below.

Alongside the disagreements, however, there is a general consensus with regard to the following five basic points.

1) In order to properly understand the national economy, economists must acknowledge the possibility of coordination between the economic and political cycles.

2) Economic-political cyclicality demands that the national economy function on a below-optimal level, from the economic standpoint; in other words, without the political drive for electoral based manipulations, the public's economic situation would be better off in comparison.

3) "The economic situation" of individuals affects their voting patterns (since, if this were not the case, manipulations directed at changing voters' sense of economic well-being would not gain electoral support). 
Advocates of the approach believe that a flourishing economy (with a low level of unemployment or rapid growth rates) helps increase the popularity of the incumbent government.

4) The voting public has either a "short memory," or limited understanding with regard to economic factors on the national level, or both. Consequently, voters will make choices based on their view of their economic situation immediately prior to elections, without taking into consideration the long-term ramifications of certain economic measures on their economic well-being in the post-election period. They will also make few demands from their elected representatives for an accounting of their unfulfilled economic promises, especially if these were made in the distant past.

5) Elected officials are motivated mainly out of a desire to further their personal advancement and are therefore willing to mortgage the nation's future to guarantee their own political status.

6) Based on the acceptance of the above premises, four key models were constructed during latter half of the 1970s; (Note 6) they all (Note 7) have a common denominator based on the following three assumptions:

a) Governments seek reelection and will make every effort to attract the maximum number of voters.

b) Voters actually prefer certain specific economic products and they express this preference on election day.

c) Governments possess the mechanisms necessary for carrying out economic manipulations that will improve their chances of reelection.

\section{The Weakness of the Common Assumption}

Even though these three assumptions are shared by the four principal models that describe economic-political cyclicality, it must be stressed that controversies, which are anything but clear-cut, surround them and raise basic questions with regard to the approach as a whole, as well as the validity of the logic underlying the models. On the surface, the first assumption appears to be almost a given, since it would be quite surprising to find a politician who was not interested in getting reelected. But a slightly more in-depth examination prompts some skepticism.

It is not at all clear that a politician's desire for reelection is the sole or even the main reason for their candidacy. Frequently the motivation derives from a combination of reasons. There might even be cases in which a candidate is not interested in being reelected (for example, when his chances of reelection are known to be poor from the outset, yet he continues running because he believes that his candidacy promotes the interests of a politician he actually favors.) Furthermore, this deliberately ignores the fact that, in addition to elected officials, the political arena includes other elements - such as bureaucrats, party machines, and the media — that also influence policy decisions; they affect, control, direct, and shape the outcomes of the political system and are also correctly perceived as partners in the various outcomes.

No less problematic is the assumption that voters express their economic preferences at the polls. The arguments in this regard are many and varied:

1) There is disagreement over degree of economic insight among the general public.

2) There is disagreement about the ostensible connection between certain economic measures and voters' economic preferences. In a large portion of the cases, different interpretations can be given to explain possible outcomes of recognized procedures.

3) There is no agreement about the degree to which economic considerations dominate voter considerations in general.

There is a dispute about the extent of the government's control over the economy, a dispute which exists both because of the uncertainty about the possibility of timing economic measures (or more precisely, the outcomes of those measures) to overlap with elections and the uncertainty about the overall impact these actions might have.

\section{The Two Dimensions of the Models}

It must be kept in mind that some of the advocates of the cyclical models accept all or some of the above arguments, while others reject them out of hand. In any event, all of them agree with the assumption that governments campaigning for reelection consider the economic element to be an electoral factor and proceed with the intention of crediting positive outcomes to themselves. Furthermore, each of the four models is based on a dichotomous perspective. This allows us to describe the differences among the approaches, albeit primarily in general terms, while relating to two distinguishing dimensions associated with cyclical functioning. The first aspect deals with the question of the extent to which governments adapt themselves to "public opinion." Two of the models assume that governments adopt a "responsive" approach, adapting their policy planning to the 
recognized preferences of their potential voters. In contrast, the other two models are based on the assumption that governments adopt a "strategic" approach that is likely to guarantee increased electoral support in the future (even if voters presently oppose a proposed stand). The second dimension deals with assumptions about voters' economic preferences. Two of the models are based on the premise that the voting public has established preferences (not necessarily dependent on a changing economic picture) that are linked to their own personal economic situation, whereas the other two models make the assumption that voter preferences change according to economic conditions, which are the outcome of previous government policy.

Opinion is divided with regard to the tools available to governments that manipulate economic-political cycles. William D. Nordhaus (1975), who builds his approach on the premise that lowering the rate of unemployment will bring about a rise in inflation rates and vice versa, (Note 8) arrives at two fundamental conclusions. First, in all democratic societies, governments will choose long-term policies that will lead to higher rates of inflation and lower rates of unemployment than what is most advantageous from an economic point of view. Nordhaus's second conclusion is that governments will seek to create the impression that there have been steady reductions in the rate of unemployment throughout their administration. In order to carry this out, they will take the following approach: shortly before elections they will raise the level of unemployment (in order to ensure a reduction in the rate of inflation); as election day approaches, they will take steps to reduce unemployment (at the cost of accelerated inflation).

Douglas Hibbs (1981), like Nordhaus, bases his approach on the Philips curve and believes that every government must deal with the choice between inflation and unemployment. But in contrast to Nordhaus, he claims that this choice depends on the political inclinations of its ministers. He maintains that the workers are harmed more by unemployment than by inflation and, therefore, he concludes that governments that lean to the "left" will work toward reducing unemployment (at the expense of accelerating inflation), whereas administrations of a more "rightist" bent will adopt the opposite approach.

The conclusion arising from an examination of Edward Tufte's (1978) model is twofold:

Governments do not have a preference as to a specific economic policy. The voters, in contrast, react to changes in the economic situation, are concerned about the sense of economic well-being produced by government measures, but rarely give much thought to anything beyond their uneasiness. Thus, Tufte maintains, governments that seek reelection adopt an approach that fosters a sense of economic well-being on the eve of balloting (increased disposable income and reduced unemployment). Furthermore, he claims that governments are especially eager to create significant changes in the public's image of the economy and (prior to elections) they do not concern themselves with the need to deal with real economic afflictions.

Peter Mosley (1976), in contrast to the three previously cited theorists, presupposes that governments are not (and do not have to be) particularly interested in economic matters with the approach of Election Day. In his opinion, the voting public does not tend to relate to the economic situation (or to make a connection between it and their pattern of voting) so long as no crisis has taken place. His conclusion is simple: a government will intervene in the economy if (and only if) an obvious crisis occurs shortly before the votes are cast.

At this stage, we can summarize by stating that aside from feelings, assessments, theories, and ideas concerning electoral prospects and political risks that government intervention in the economy may produce for the benefit/detriment of elected representatives in democratic countries, we have no empirical findings, which prove that this type of intervention (no matter what its format) has produced real electoral dividends for its initiators. Nevertheless, it is possible to conclude with a great deal of certainty that in most Western countries, broad sectors of the population share the idea that economic-political cyclicality is an established fact. As in the aphorism "success has many parents, failure is an orphan," the tendency of the general public to be occupied with the issue of the legitimacy of government intervention in the economy does not, in most cases, relate to the debate about the preferred economic theory, unless the society is in the throes of an economic crisis. It is as if political intervention (which considers how best to maximize electoral gains) is legitimate and necessary when it leads to prosperity and economic well-being, whereas it is a risky matter that requires close public scrutiny when it gives rise to economic problems (of any nature).

\section{Conclusion}

For more than three decades, a theoretical debate has been going on about the idea of economic-political cyclicality, with the main differences of opinion revolving around several key questions:

1) What, if any, logic underlies the purpose of coordinating between the cycles?

2) Do the means exist that enable such coordination? 
3) Is such coordination capable of guaranteeing definite political benefit?

4) Are the "beneficiaries" and "payers" (necessarily) identical groups of people?

5) Can the manipulation of economic-political cycles be proved or disproved?

In addition to this basic dispute, We presented the disagreements prevalent among the supporters of this approach, which also touch on the above questions. We explained that: they agree about the existence of the political logic of such manipulation, although they are divided as to its nature; they agree that there are operative means of coordinating the cycles, but disagree about their form and the degree of their impact; they disagree about the different populations affected ("benefactors" and "payers"); and there is no consensus about the ability to prove that cyclicality is being manipulated in a given time and place.

\section{References}

Alesina, A., \& Rosenthal, H. (1995). Partisan Politics, Divided Government, and the Economy. New York: Cambridge University Press. http://dx.doi.org/10.1017/CBO9780511720512

Alt, J. E., \& Chrystal, K. A. (1983). Political Economics. Los Angeles: University of California Press.

Drazen, A. (2000). Political Economy in Macroeconomics. Princeton: Princeton University Press.

Drazen, A. (2002, September). Political Economy of Anti-Cyclical Fiscal Policy. The Economic Quarterly, 49(3).

Esping-Andersen, G. (2000). Social Foundations of Postindustrial Economies. Oxford: Oxford University Press.

Esping-Anderson, G. (1993). The Three Worlds of Welfare Capitalism. New Brunswick NJ: Princeton University Press.

Greenfeld, L. (2001). The Spirit of Capitalism. Cambridge, MA and London: Cambridge University Press.

Hibbs, D. (1977). Political Parties and Macroeconomic Policy. American Political Science Review, 71, 1467-87. http://dx.doi.org/10.1017/S0003055400269712

Hibbs, D. (1979). Letter. American Political Science Review, 73, 185-90. http://dx.doi.org/10.1017/S0003055400271852

Hibbs, D., \& Madsen, H. (1981). Public Reactions to the Growth of Taxation and Government Expenditure. World Politics, 33, 413-35. http://dx.doi.org/10.2307/2010209

Keynes, J. M. (1936). The General Theory of Employment, Interest, and Money. London: Macmillan.

Liviatan, N. (2002, September). A Symposium on Anti-Cyclical Economic Policy in Israel. The Economic Quarterly, 49(3).

Melnick, R. (2002, September). Business Cycles in Israel: Monetary and Fiscal Approach. The Economic Quarterly, 49(3).

Mosley, P. (1976). Towards a Satisfying Theory of Economic Policy. Economic Journal, 86. http://dx.doi.org/10.2307/2230951

Niskanen, W. (1971). Bureaucracy and Representative Government. Chicago: Aldine-Atherton.

Nordhaus, W. D. (1975). The Political Business Cycle. Review of Economic Studies, 42, 169-90. http://dx.doi.org/10.2307/2296528

Olson, M. (1965). The Logic of Collective Action. Cambridge, MA: Harvard University Press.

Persson, T., \& Tabellini, G. (2002). Political Economics: Explaining Economic Policy. Cambridge: The MIT Press.

Persson, T., \& Tabellini, G. (Eds.). (1994). Monetary and Fiscal Policy. Cambridge, MA: MIT Press.

Smith, A. (1937). An Inquiry into the Nature and Causes of the Wealth of Nations. New York: The Modern Library.

Tufte, E. (1978). The Political Control of the Economy. Princeton: Princeton University Press.

Wilensky, H. (2002). Rich Democracies. Berkeley: University of California Press. 


\section{Notes}

Note 1. It should be noted that Adam Smith did not completely reject all forms of government intervention, considering it unavoidable in cases such as ensuring the security of a country's citizens (domestically and internationally), and providing education and other public services that the marketplace does not support. For further details, see Smith (1937, vol.5, chaps. 1-2). Nonetheless, he rejected government intervention in the marketplace in principle, accepting it only when there was no other choice and stating unequivocally that any intervention is damaging and requires valid justification.

Note 2. Liviatan's (2002) "anti-cyclical” concept parallels the dispute between the supporters and opponents of the Keynesian theory about government intervention in the economy. Anti-cyclical policy is in effect another name for the tendency of governments to promote a reduction or expansion of market activity when the business cycle does not suit the political or social needs of the times (as determined by the political decision-makers).

Note 3. The recognition of human and civil rights as distinct from vested rights that devolve on the basis of national affiliation (one of the main byproducts of the French Revolution) contributed to the development and final recognition of the right to accumulate private property, and the distinction between public property and privately owned property. For these (and other) reasons, the economic approach that upholds competition is linked to the (individual or national) trend toward the liberal outlook that greatly expands the borders of individuals and limits, in parallel, the control of the public. For more detail on this topic, see Greenfeld (2001, 105-224).

Note 4. "Public Goods" as defined by Olson (1965).

Note 5. For more detail on this issue, see Esping-Anderson (1993, 144-61).

Note 6. During the 1980s and 1990s additional models were developed to explain the phenomenon. Yet, they were not groundbreaking or remarkable, but rather represented a range of "improvements" on existing models. For a more detailed discussion, see Alesina and Rosenthal (1995); Persson and Tabellini (1994).

Note 7. On these key models, see Nordhaus (1975); Hibbs (1977; 1979); Hibbs and Madsen (1981); Tufte (1978); Mosley (1976), as cited in Alt and Chrystal (1983, 103-25).

Note 8. This premise relies on the Phillip's curve (named after its developer) that includes the option of switching between inflation and unemployment. This theoretical perspective is reflected in the assertion that a government has the ability to choose the position of the national economy vis-à-vis these two variables and that it attempts to change the "natural" situation of the marketplace on the basis of this preference. It is important to note that during the last thirty years, data has been collected which indicates a connection between the two variables. At the same time, many prominent neo-monetary economists reject the entire approach.

\section{Copyrights}

Copyright for this article is retained by the author(s), with first publication rights granted to the journal.

This is an open-access article distributed under the terms and conditions of the Creative Commons Attribution license (http://creativecommons.org/licenses/by/4.0/). 